\title{
Research of University Librarian's Job Burnout and Its Adjustment
}

\author{
Beidi Zhang \\ Shandong Normal University, Jinan, Shandong, 250014
}

\begin{abstract}
University librarians engaged in university teachers and students as the main service object of service work, occupational characteristics and professional behavior makes it easy to produce job burnout. This paper from the university librarian job burnout performance, analysis of the causes of job burnout puts forward the coping strategy.
\end{abstract}

Keywords: Librarian, Job Burnout, Adjustment Management

\section{Introduction}

With the growth of librarians working in the library, often no longer work at the beginning of the lofty ideals, but also more indifferent to the service of education, and more tired of borrowing, and more on life and Career status of the helpless, more on the self-professional ability and professional level of indifferent. The emergence of these psychological and sensory, it is the typical manifestation of librarian job burnout. Librarians, once the job burnout, the physiological and psychological will produce a series of changes in the negative psychological reactions resulting in decreased body function, emotional tension, anxiety, irritability, easy to nervousness, and even physical discomfort, fatigue, insomnia Of the sub-health state, and then induce neurosis, and even heavy mental illness, physical illness, resulting in the work of librarians, quality of life decreased. Librarian job burnout, once formed, will tend to dissatisfaction with the work, resulting in avoidance of negative state of mind. The work of perfunctory, the work of objects and the environment to take cold, neglected attitude, but relies on a kind of inertia to work, without any initiative, can not use a positive attitude to 
serve the reader. Librarians work on the reader, every day and the reader to deal with their words and deeds will have a subtle impact on the reader, librarians of the professional nature of burnout will naturally affect the reader.

\section{Librarians' Job Burnout: Its Meanings and Manifestations}

Fuldengboge that burnout is a worker can not cope with the outside world beyond personal energy and resources of the excessive demands arising from the physical, mental, emotional, emotional and behavioral aspects of mental and physical exhaustion, the American scholar Maslaki that, Job burnout is a behavioral response to people in an industry that requires continuous, intense interaction with others who experience emotional fatigue due to inability to respond to stress in a timely and effective manner, and According to the above definition of burnout, the author believes that librarians burnout is because the librarians can not effectively alleviate the work of the individual in a timely and effective way to alleviate the problem of job burnout, which can not be achieved in a timely manner. Stress or properly handle a variety of frustration at work experience a mental and physical exhaustion of the emotional state of the librarian in a job for a long time or work requirements are too harsh, will lead to librarians produce a mood of mental and physical exhaustion, The librarians are the implementers of library services, and some librarians are troubled by the mental fatigue of their job burnout, which seriously affect their work, life and life, and they can not work well.

It is another characteristic of the current job burnout of the librarians that the reader is indifferent, cynical, deliberately keeping a certain distance from the work and other work-related personnel, not enthusiastic about the work and input, and doubting the meaning of his work. In the university, compared with the teachers, the degree of the librarian's attention to the school is obviously not high, the treatment is obviously low, in the public library, the library is the reader that is a place to borrow books, librarians social status high. The reader's prejudice to library knowledge and the special information needs of some readers make it difficult for the low-quality librarians to provide satisfactory services for the readers. They are very indifferent to the readers and do not take the initiative to solve problems for the readers. , But passively for the reader services. Such as Wang Xuelun, Zhang Tingguang and Ren Junyi, conducted a questionnaire survey on librarians from Yantai University, Yantai Campus, Yantai Campus of Yantai University, Yantai University, Yantai City, Shandong Province, and found that librarians had a higher average cynicism, College librarians feel more cynical. Some librarians tend to be negative self-evaluation, that they can not effectively qualified for work, hesitant, too. With the rapid development of modern science and technology, the concept and service mode of library services are constantly updating. Some librarians are unable to adapt to the new era of library work because of their aging knowledge and obsolete ideas. Personal ability and the level of innovation and development of stagnation are resulting in the work of powerless, accustomed to passive coping. 


\section{An Analysis of the Causes of Librarians' Job Burnout}

As the work of librarians is a service work, its social benefits are hidden and long cycle characteristics, the achievements of librarians with ambiguity and delay is inevitable. So the librarian's work is often seen as dispensable. Although the services of librarians have saved teachers and researchers a great deal of time and increased their working efficiency, the efforts of librarians often can not be reflected well. A considerable number of readers regard the service work of libraries as low Level, simple repetition of labor, and then look down on librarians, do not respect their labor. Librarians do not receive the necessary understanding and respect, which will inevitably lead to depressed librarians, loss of enthusiasm for work, resulting in a sense of loss. Coupled with the work of the library are a number of tedious duplication of work, long-term work in this state will make people lose patience and interest, resulting in a tired state of mind, which engaged in the job burnout.

The society has a direct impact on the development of the library cause, and the inherent thinking is that the library and information science belongs to the low-level subject group, and its service has been hovering in the literature-based service and low-level of the borrow also. Although the industry has repeatedly stressed the library's academic institutions, but because of the social history of the various constraints, its academic spirit, academic atmosphere and service level has been unable to achieve the desired level. Librarians do not need professional theoretical knowledge, borrowing also is the work of all the "atmosphere, the heart is difficult to balance, so the psychology of the library staff in the cultural groups, especially in the professional education of the staff, Loss, burnout awareness gradually formed. In addition, in recent years, with the popularization of information technology and the rapid development of mass media, the library is not the only source of information, many teachers and students began to get used to the Internet search all kinds of knowledge and information on the degree of dependence on the library reduced, There has been a wave of denial of the subject of library science. This contempt for the library directly led to the mentality of the librarians, their career prospects pessimism and disappointment, the emergence of a sense of professional burnout is inevitable.

University library staff not only the existence of the overall qualifications, job title structure is not up to the phenomenon, and there is the academic level and the actual level does not match the phenomenon, such as knowledge aging, knowledge depletion and other phenomena. With the expansion of colleges and universities, but also the face of different levels of student readers a wide range of needs. At the same time, the educational reform in our country puts forward higher requirements to the librarians' quality, which makes the librarians feel helpless when they provide the deep-level literature service, and can not finish the work well. The task to feel the depletion of knowledge and methods of dealing with student problems exhausted, and ultimately produce job burnout. 


\section{Librarian Job Burnout Coping Strategies}

Service industry research shows that emotions directly affect the performance of employees. When employees are in a bad mood, they often treat their customers with indifference, which affects their work efficiency and service quality. With the rise of information technology and the Internet and rapid development of library services and service means of continuous innovation. At the same time, due to the continuous improvement of the quality of the public, the reader's expectations of the library is also increasing, making the library employees than other service industries are facing more challenges. The increase of work pressure will affect the mood of librarians, and the fluctuation of emotions inevitably affects the librarians' thinking and behavior, which affects the service quality of librarians. Therefore, strengthening the research and management of the librarians 'emotions is an important link to eliminate the negative influence of the job burnout on the librarians' potentiality and quality improvement.

An important part of the management mechanism of university library is the incentive mechanism. Library incentive mechanism is the main manager of the library to the librarian to take the initiative to stimulate their initiative, initiative and creativity of a comprehensive behavioral mechanism]. Including motivation, motivation, participation motivation, knowledge motivation, self-motivation and so on. The motivation of the target can stimulate the librarian's work enthusiasm; the work motivation can make the librarian feel happy from the work; the participation encouragement can let the librarian participate in the decisionmaking, is helpful to the "self-actualization" needs; the knowledge encouragement can stimulate and enhance the librarian's Self-motivation can help achieve the individual's ideals and aspirations, to maximize their potential.

At the same time, also determines the attractiveness of the occupation and engage in the professional social status. First of all, people engaged in highposition career vulnerable to people's envy, respect and privilege, he himself is more proud and superior, and thus love their career. Therefore, to librarians love their jobs, must be through the development of preferential policies to improve the economic income of librarians and other treatment; Secondly, to do public opinion propaganda work, and guide the school correct understanding and treatment of library work, given its due status And librarians development to create a good environment; Third, strengthen the librarian team building, improve the overall quality, and establish a good librarian image, and create a favorable environmental tendencies and social atmosphere, so that librarians in a harmonious environment The formation of professional pride, and then in a healthy and positive emotions in the library work, away from job burnout.

University Libraries should carry out different forms and scope of job knowledge and technical knowledge training. Librarians often come from different classes, their quality varies widely, the degree of knowledge vary, and many librarians of multimedia, computer, network and other technology is very strange, and master these new knowledge and new skills and the need for a process, it must be Follow the principle of combining long and short training. In the course of training, the librarians' self-confidence and work enthusiasm are 
enhanced to make them realize the importance and necessity of continuing education so that the librarians can accept the new work content and master the new working methods. At the same time create conditions for librarians to communicate, can effectively improve the overall learning efficiency of librarians. Only as soon as possible to adapt to the new situation, in order to avoid the greatest extent, librarians have a job burnout.

Librarians must emphasize the importance of lifelong learning, relying on the rich literature resources of libraries and the knowledge groups of colleges and universities in the rapid development of information technology. Librarians must have a high level of knowledge and knowledge structure. , Continuous learning. Not only to learn library information science expertise, but also to master a certain degree of computer theory, operation and other aspects of knowledge, master the edge disciplines and cutting-edge disciplines of development, improve their overall quality, so that their work in the initiative, Through the creative information service work, and earnestly improve the reader's satisfaction with the library, in the quality service to reshape the image and realize their own value, so as to effectively suppress the burnout.

\section{Conclusion}

Librarian job burnout is a common psychological problem in the career of librarians. The librarian's own efforts are very important in relieving and eliminating librarian's job burnout. The solution of the bell is still needed. In the face of various pressures, librarians should correctly understand the pressure, take active measures to deal with negative emotions, effectively solve their own problems of job burnout, work hard to achieve a healthy life, to contribute to the development of the library Out of their own should be a force.

\section{References}

[1] Tao Wenping. Personal Interference of Self-Efficacy to University Librarians' Job Burnout [J]. Journal of Library Science, 4(2), pp. 24-31, 2006

The Relationship between Job Burnout and Self-esteem and Social Support of Professional Mothers [J] .Psychological Development and Education, 1(4), pp. 25-31, 2008

[3] Wang Shouguo. Analysis of Librarians in Professional Librarianship causes [J]. Sci-Tech Information Development \& Economy, 36(4), pp.22-40, 2007

[4] Liu Meitao. The University Librarian Job Burnout [J]. Academic Libraries, 6(2), pp. 11-13, 2007

[5] Cao Lin. University Librarian job burnout and self-potential activation [J]. Journal of Wenshan Teachers College, 3(4), pp. 14-23, 2007 